\title{
Pembuatan Biodiesel dari Minyak Jelantah Menggunakan Adsorben Karbon Aktif dan Pembuatan Triasetin dengan Katalis Asam Nitrat
}

\section{Biodiesel from Waste Cooking Oil using Activate Carbon as Adsorbent and Synthesis of Triaacetin using Nitric Acid as Catalyst}

\author{
Novi Nuraeni, Yenny Febriani Yun*, dan Dewi Meliati Agustini \\ Jurusan Kimia, Fakultas Sains dan Informatika, Universitas Jenderal Achmad Yani \\ Jalan Terusan Jenderal Sudirman, Cimahi, 40285, Indonesia \\ *E-mail: yenny.febriani@lecture.unjani.ac.id
}

DOI: https://doi.org/10.26874/jkk.v2i1.26

Received: 11 May 2019, Revised: 31 May 2019, Accepted: 31 May 2019, Online: 31 May 2019

\begin{abstract}
Abstrak
Minyak jelantah sebagai limbah dari minyak bekas penggorengan mengandung kadar asam lemak bebas yang tinggi. Upaya pemanfaatan limbah minyak jelantah adalah dengan mengubahnya menjadi biodiesel dan triasetin. Pembuatan biodiesel dilakukan dengan penambahan karbon aktif sebanyak $4 \%$ berat minyak dan pengadukan selama 1 jam pada suhu $90-100{ }^{\circ} \mathrm{C}$, dilanjutkan dengan proses transesterifikasi. Proses tersebut mampu mengubah minyak jelantah menjadi biodiesel sebesar 95,28 \% berat minyak, dengan titik nyala $179{ }^{\circ} \mathrm{C}$, kadar air $0,13 \%$, bilangan asam 0,59 , gliserol total $0,03 \%$ dan gliserol hasil samping sebesar 10,05\% berat minyak. Triasetin disintesis dengan cara esterifikasi gliserol hasil samping pembuatan biodiesel dengan asam asetat dengan rasio mol $1: 7$ pada suhu $120^{\circ} \mathrm{C}$ menggunakan katalis asam nitrat $5 \%$ berat gliserol. Esterifikasi triasetin menunjukkan \% konversi asam asetat yang rendah, yaitu sebesar $24,05 \%$. Hal ini berarti asam nitrat tidak baik digunakan sebagai katalis dalam proses esterifikasi triasetin.
\end{abstract}

Kata kunci: biodiesel, triasetin, minyak jelantah, karbon aktif, gliserol

\begin{abstract}
Waste cooking oil is a waste of frying oil that is containing high free fatty acids (\% FFA). The waste could be made to be useful as biodiesel and triacetin. Biodiesel was produced by addition of $4 \%$ (oil weight) activated carbon with stirring for lhour at $90-100^{\circ} \mathrm{C}$ then transesterification of waste cooking oil. The results showed the yield of the biodiesel was $95.28 \%$ with flash point $179^{\circ} \mathrm{C}$, water content 0.13 $\%$, acid value 0.59, total glycerol $0.03 \%$, and the by-product glycerol $10.05 \%$ (oil weight). Triacetin was synthesized by esterification of the glycerol with acetic acid with mol ratio $1: 7$ at $120^{\circ} \mathrm{C}$ used nitric acid catalyst (5\% glycerol weight). The results showed that the conversion of acetic acid was low, 24.05 $\%$. That showed nitric acid could be a good catalyst in the esterification of triacetin.
\end{abstract}

Keywords: Biodiesel, triacetin, waste cooking oil, activated carbon, glycerol 


\section{Pendahuluan}

Bahan bakar minyak (BBM) merupakan energi yang paling banyak dikonsumsi oleh masyarakat di dunia. Menurut Kementrian Badan Usaha Milik Negara (BUMN), kapasitas kilang minyak di Indonesia hanya mampu memenuhi $50 \%$ dari kebutuhannya, sisanya dipenuhi dengan subsidi impor. Oleh karena itu, perlu adanya upaya mencari energi alternatif yang bersifat terbarukan (renewable). Energi terbarukan yang dapat menggantikan BBM ialah biofuel. Biofuel adalah energi terbarukan yang terbentuk dari materi hidup. Biofuel terdiri dari bioetanol, biogas, dan biodiesel. Dari ketiga jenis biofuel tersebut, biodiesel merupakan energi terbarukan yang dapat menggantikan BBM [1]. Biodiesel ialah energi terbarukan berbentuk minyak yang terbentuk dari minyak nabati atau lemak hewani melalui transesterifikasi suatu alkohol. Minyak nabati yang biasa digunakan ialah minyak kedelai, minyak kelapa, atau minyak kelapa sawit. Sementara itu, ada alternatif lain dari bahan limbah yang dapat berperan sama dengan minyakminyak tersebut, yaitu minyak jelantah [2].

Minyak jelantah merupakan limbah dari penggunaan minyak goreng baik dari kelapa atau dari kelapa sawit. Pembuatan biodiesel dengan bahan baku minyak jelantah dipengaruhi oleh peningkatan kadar asam lemak bebas hasil oksidasi dari minyak jelantah itu sendiri. Peningkatan kadar asam lemak bebas dapat mengganggu proses trans-esterifikasi. Syarat kadar asam lemak bebas pada bahan baku minyak atau lemak dalam pembuatan biodiesel ialah maksimal $1 \%$ [3]. Oleh karena itu, diperlukan perlakuan awal yang dapat menurunkannya menggunakan adsorben. Beberapa adsorben yang dapat digunakan di antaranya bleaching earth, zeolit, bentonit, dan karbon aktif. Adsorben yang paling banyak digunakan adalah karbon aktif karena harganya yang murah dan efektif untuk perlakuan awal minyak jelantah [4].

Jika minyak jelantah ditransesterifikasi dengan suatu alkohol maka akan menghasilkan biodiesel dan gliserol. Gliserol banyak dimanfaatkan dalam industri makanan, farmasi dan kosmetik, namun harga jualnya relatif rendah. Jika gliserol diesterifikasi dengan senyawa asam karboksilat maka dapat diperoleh derivatnya yang memiliki harga jual lebih tinggi. Dengan demikian, pemanfaatan hasil samping pembuatan biodiesel ini akan lebih menguntungkan [5].

Salah satu derivat gliserol ialah triasetin (1,2,3-triasetoksipropana). Triasetin dapat dibuat dengan cara esterifikasi gliserol dengan asam asetat. Kegunaan triasetin ini ialah sebagai bahan aditif untuk meningkatkan cold flow, menurunkan viskositas biodiesel, anti-knock, mening-katkan nilai oktan pada bensin sebagai alternatif dari alkil eter komersial, serta bahan aditif dalam industri makanan, farmasi dan kosmetik [6].

Pembuatan triasetin dengan esterifikasi gliserol dan asam asetat memerlukan katalis agar reaksi berjalan dengan baik. Berdasarkan hasil penelitian Wepoh [7], katalis yang paling baik digunakan untuk memperoleh konversi triasetin ialah asam kuat homogenus. Widayat dkk. [5] juga telah melakukan esterifikasi dengan perbandingan gliserol dan asam asetat $1: 7$ menggunakan katalis asam sulfat $5 \%$ selama 50 menit pada suhu $120^{\circ} \mathrm{C}$ menghasilkan perolehan masing-masing $67,6 \%$. Penggunaan katalis tersebut memerlukan biaya yang tinggi sehingga kurang menguntungkan dari segi ekonomis produksi biodiesel.

Katalis asam nitrat $\left(\mathrm{HNO}_{3}\right)$ sebagai salah satu asam kuat dengan harga relatif murah belum pernah digunakan, sehingga perlu adanya penelitian untuk melihat pengaruh asam nitrat terhadap konversi triasetin. Asam nitrat dapat terurai menjadi ion $\mathrm{H}^{+}$dan ${ }^{-} \mathrm{O}-\mathrm{NO}_{2}$ yang stabil oleh adanya resonansi [8]. Karakter katalis asam nitrat ini mirip dengan asam sulfat yang ion sulfatnya $\left({ }^{-} \mathrm{O}-\mathrm{SO}_{3}\right)$ juga stabil oleh resonansi. Jika ion $\mathrm{H}^{+}$pada katalis stabil maka reaksi akan berjalan ke arah produk dengan baik.

\section{Metode Penelitian}

\subsection{Bahan dan Alat}

Alat yang digunakan meliputi satu set alat refluks, corong pisah, neraca analitik, termometer, oven, piknometer, hot plate dengan stirrer, Gas Chromatography Spectrophotometry Massa (GCMS) Agilent 7890A, spektroskopi Fourier Tranform Infrared (FTIR) Shimadzu 8400. Bahan yang digunakan ialah minyak jelantah, minyak kelapa sawit murni, Sunco, karbon aktif, metanol $\left(\mathrm{CH}_{3} \mathrm{OH}\right)$ p.a, kalium hidroksida $(\mathrm{KOH})$ p.a, akuades, asam nitrat $\left(\mathrm{HNO}_{3}\right)$ p.a Merck. Asam asetat $\left(\mathrm{CH}_{3} \mathrm{COOH}\right)$ p.a, etanol $\left(\mathrm{CH}_{3} \mathrm{CH}_{2} \mathrm{OH}\right)$ p.a, toluena $\left(\mathrm{C}_{7} \mathrm{H}_{8}\right)$ p.a, natrium hidroksida $(\mathrm{NaOH})$ p.a, phenolftalein (PP), dan kertas saring Whatman 42.

\subsection{Perlakuan Awal Minyak Jelantah}

Penjernihan minyak jelantah mengikuti metoda yang dilakukan oleh Majid [4] dengan cara menyaring minyak menggunakan kain. Kemudian karbon aktif (adsorben) ditimbang masing-masing $3 \% ; 4 \% ; 5 \% ; 6 \%$ dan $7 \%$ (b/b minyak jelantah). 
Karbon aktif diaktivasi dengan pemanasan dalam oven pada suhu $100{ }^{\circ} \mathrm{C}$ selama 1 jam. Minyak jelantah sebanyak 200 gram yang sudah disaring dipanaskan pada suhu $70{ }^{\circ} \mathrm{C}$ dalam beaker glass $500 \mathrm{ml}$ sambil diaduk menggunakan magnetic stirer. Karbon aktif dicampurkan ke dalam minyak jelantah dan dipanaskan sampai suhu 90$100{ }^{\circ} \mathrm{C}$ di atas hot plate sambil diaduk dengan magnetic stirer selama 1 jam. Minyak disaring menggunakan kertas saring halus.

\subsection{Pembuatan Biodiesel}

Pembuatan metoksida mengacu pada metode yang dilakukan oleh Srivastava dan Prasad [9] transesterifikasi metanol dan minyak jelantah dengan perbandingan $1: 6$ mol dan menggunakan katalis $\mathrm{KOH} 1 \% \mathrm{~b} / \mathrm{b}$ minyak jelantah. Transesterifikasi dilakukan selama 60 menit pada suhu $65{ }^{\circ} \mathrm{C}$. Pendiaman dilakukan terhadap hasil transesterifikasi selama \pm 1 jam agar gliserol mengendap dengan sempurna dalam corong pisah. Gliserol dengan biodiesel dipisahkan. Berdasarkan metode penelitian Aziz (2007), biodiesel dikeringkan dengan pemanasan pada suhu $105{ }^{\circ} \mathrm{C}$ dalam oven sampai berat stabil. Analisa dilakukan dengan GCMS serta menentukan bilangan asam (FBI-A01-03), kadar air (AOAC, 1995) titik nyala (ASTM D 93, 2002), dan kadar gliserol (FBI-A02-03).

\subsection{Pembuatan Gliserol}

Mengacu pada metode penelitian yang dilakukan oleh Khairiti (2006), gliserol dimurnikan dengan menambahkan akuades dengan perbandingan $2: 3$. Karbon aktif ditambahkan sebanyak $5 \%$ berat gliserol, lalu diaduk selama 45 menit kemudian disaring dengan kertas saring. Crude glycerol dikeringkan dalam oven pada suhu $105{ }^{\circ} \mathrm{C}$ sampai bobot stabil. Struktur molekul senyawa gliserol yang berhasil diesterifikasi dan dimurnikan dianalisa dengan cara interpretasi data spektroskopi Fourier Transform Infrared (FTIR), analisa densitas (SNI 01-2891-1992) serta kadar air dengan Metode Karl Fischer (AOAC, 1995).

\subsection{Pembuatan Triasetin}

Pembuatan triasetin mengikuti metode yang dilakukan oleh Satriadi [10] dengan perbandingan gliserol dan asam asetat sebesar 1:7 mol. Gliserol dalam labu leher tiga dipanaskan sampai suhu 80 ${ }^{\circ} \mathrm{C}$. Asam asetat p.a. dipanaskan dalam
Erlenmeyer sampai suhu $80{ }^{\circ} \mathrm{C}$. Asam asetat dicampurkan dengan gliserol di dalam labu leher tiga. Asam nitrat ditambahkan sebanyak $5 \%$ berat gliserol. Campuran tersebut direfluks pada suhu $120{ }^{\circ} \mathrm{C}$ selama 100 menit. Struktur molekul senyawa triasetin yang berhasil diesterifikasi dimurnikan dan dianalisa dengan analisis spektroskopi Fourier Transform Infrared (FTIR) dan analisa kuantitatif dengan titrasi asidi alkalimetri menggunakan titran $\mathrm{NaOH} 0,5 \mathrm{~N}$.

\section{Hasil dan Diskusi}

\subsection{Hasil Perlakuan Awal Minyak Jelantah} dengan Karbon Aktif

Hasil pemurnian dengan karbon aktif menunjukkan bahwa dengan konsentrasi $4 \%(\mathrm{~b} / \mathrm{b}$ minyak jelantah), karbon aktif mampu menurunkan \% FFA dari 2,14\% menjadi $0,96 \%$ dalam waktu pengadukan selama 1 jam pada suhu $90-100^{\circ} \mathrm{C}$. Hasil penurunan $\%$ FFA tersebut sudah memenuhi standar, yaitu kurang dari $1 \%$ sehingga minyak jelantah dapat ditransesterifikasi [3].

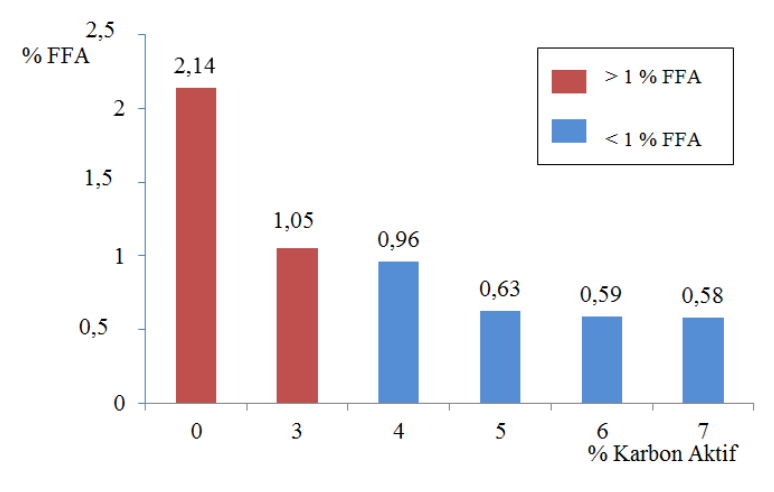

Gambar 1. Kurva Penurunan Asam Lemak Bebas

\subsection{Hasil Transesterifikasi Biodiesel}

Hasil penelitian menunjukkan rendemen yang cukup tinggi, yaitu 95,28\%. Metode penelitian ini menghasilkan biodiesel lebih banyak daripada menggunakan bahan baku CPO Off Grade yang dilakukan oleh Arita dkk. [11] dengan suhu yang lebih rendah, yaitu $50-58{ }^{\circ} \mathrm{C}$, yaitu sebesar $81,94 \%$.

Hasil analisis sampel biodiesel dari minyak jelantah (MJ) dibandingkan dengan biodiesel dari minyak kelapa sawit (MKS). Keduanya menghasilkan biodiesel dengan titik nyala, bilangan asam dan gliserol total yang memenuhi standar ASTM D6751-02. Namun parameter kadar air tidak memenuhi standar tersebut sehingga diperlukan perbaikan pada tahap 
pemurnian biodiesel. Perbandingan sifat fisik dan kimia biodiesel MJ dan MKS disajikan pada Tabel 1.

Tabel 1. Sifat Fisik dan Kimia Biodiesel Hasil Transesterifikasi [12]

\begin{tabular}{|c|c|c|c|c|}
\hline \multirow{3}{*}{$\begin{array}{l}\text { Parameter } \\
\text { \& Metode }\end{array}$} & \multirow{3}{*}{ Satuan } & \multirow{2}{*}{\multicolumn{2}{|c|}{$\begin{array}{c}\text { Hasil Analisa } \\
\text { Biodiesel }\end{array}$}} & \multirow{3}{*}{$\begin{array}{c}\text { ASTM } \\
\text { D6751-02 }\end{array}$} \\
\hline & & & & \\
\hline & & MJ & MKS & \\
\hline $\begin{array}{l}\text { Titik Nyala } \\
\text { ASTM D93 }\end{array}$ & ${ }^{\circ} \mathrm{C}$ & 179 & 176 & Min. 130 \\
\hline $\begin{array}{l}\text { Kadar Air } \\
\text { ASTM D95 }\end{array}$ & $\% \mathrm{v}$ & 0,130 & 0,130 & $\begin{array}{l}\text { Maks. } \\
0,050\end{array}$ \\
\hline $\begin{array}{l}\text { Bilangan } \\
\text { Asam } \\
\text { FBI-A01-03 }\end{array}$ & $\begin{array}{c}\mathrm{mg} \\
\mathrm{KOH} / \mathrm{g}\end{array}$ & 0,59 & 0,65 & $\begin{array}{c}\text { Maks. } \\
0,80\end{array}$ \\
\hline $\begin{array}{l}\text { Gliserol } \\
\text { Total } \\
\text { FBI-A02-03 }\end{array}$ & $\% \mathrm{~b}$ & 0,03 & 0,07 & $\begin{array}{l}\text { Maks. } \\
0,240\end{array}$ \\
\hline
\end{tabular}

Kromatogram yang diperoleh menunjukkan adanya puncak-puncak dengan waktu retensi dan luas puncak seperti pada tabel Tabel 2 . Berdasarkan data tersebut diduga biodiesel hasil sintesis ini mengandung senyawa dengan kelimpahan yang paling tinggi dimiliki metil oleat. Tiap puncak hasil GC, dianalisis Spektroskopi Massa atau Mass Spectroscopy (MS) dan dibandingkan dengan data base yang ada pada instrumen uji.

Tabel 2. Senyawa-senyawa yang Terdapat dalam Biodiesel dari Hasil Analisis GCMS [13]

\begin{tabular}{ccccl}
\cline { 1 - 4 } \multicolumn{2}{c}{ Biodiesel-MJ } & \multicolumn{2}{c}{ Biodiesel-MKS } & \multicolumn{1}{c}{$\begin{array}{c}\text { Nama } \\
\text { Senyawa }\end{array}$} \\
\cline { 1 - 4 } $\mathbf{t} \mathbf{R}$ & $\mathbf{A}$ & $\mathbf{t R}$ & $\mathbf{A}$ & \\
& 0,32 & 11,198 & 0,33 & Metil Laurat \\
13,740 & 1,62 & 13,740 & 1,51 & Metil Miristat \\
16,125 & 0,84 & 16,123 & 0,20 & Metil \\
& & & & Palmitoleat \\
16,580 & 31,35 & 16,555 & 32,81 & Metil Palmitat \\
20,058 & 16,32 & 20,047 & 15,06 & Metil Linoleat \\
20,314 & 42,21 & 20,277 & 43,79 & Metil Oleat \\
20,654 & 6,55 & 20,633 & 5,93 & Metil Stearat \\
23,264 & 0,28 & - & - & cis-11-Metil \\
& & & & Eikosenat \\
23,583 & 0,51 & 23,583 & 0,37 & Metil \\
& & & & Arakhidat \\
\hline
\end{tabular}

Ket: $\mathrm{t}_{\mathrm{R}}=$ waktu retensi (menit)

$\mathrm{A}=$ Persentase luas puncak $(\%)$

\subsection{Hasil Karakterisai Gliserol}

Proses pencampuran karbon aktif dengan gliserol dibantu dengan penambahan air. Penambahan air ini berfungsi untuk menurunkan densitas gliserol sehingga diharapkan proses penyerapan pengotor dengan karbon aktif menjadi lebih baik. Karbon aktif ini dapat menyerap pigmen hitam yang terlarut dalam gliserol. Perbandingan hasil pemurnian gliserol dapat dilihat pada Tabel 3 .

Tabel 3. Perbandingan Sifat Fisik Crude Gliserol dengan Gliserol setelah Pemurnian

\begin{tabular}{lccc}
\hline Sifat Fisik & $\begin{array}{l}\text { Crude } \\
\text { Gliserol }\end{array}$ & $\begin{array}{l}\text { Gliserol } \\
\text { Setelah } \\
\text { Pemurnian }\end{array}$ & $\begin{array}{l}\text { Gliserol } \\
\text { Teknis }\end{array}$ \\
\hline $\begin{array}{l}\text { Densitas } \\
(\mathrm{g} / \mathrm{mL})\end{array}$ & 1,244 & 1,230 & 1,262 \\
$\begin{array}{l}\text { Kadar Air } \\
(\% \mathrm{v})\end{array}$ & 0,50 & 0,78 & 0,05 \\
Warna & $\begin{array}{c}\text { Coklat } \\
\text { Kehitaman }\end{array}$ & $\begin{array}{c}\text { Kuning } \\
\text { Kecoklatan }\end{array}$ & Bening \\
\hline
\end{tabular}

Karakterisasi ini bertujuan untuk membuktikan bahwa benar hasil samping pembuatan biodiesel pada penelitian ini ialah gliserol. Terbukti dengan hasil spektrum-IR terdapat ikatan C-O, C-H, dan O-H alkohol yang menyusun struktur molekul gliserol seperti ditampilkan pada Gambar 2 dan hasil interpretasi dijelaskan pada Tabel 4.

\subsection{Hasil Esterifikasi Triasetin}

Senyawa triasetin mempunyai rumus bangun seperti pada Gambar 4. Hasil analisis spektrum serapan radiasi inframerah disajikan dalam Gambar 3. Senyawa ini terdiri atas gugus ester, gugus metil serta ikatan atom karbon dengan atom karbon. Bilangan gelombang hasil karakterisasi puncak-puncak sampel produk reaksi disajikan dalam Tabel 5.

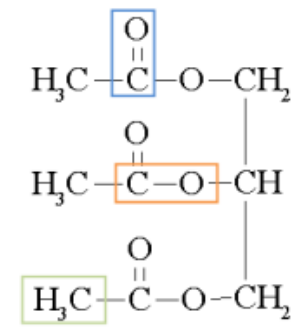

Gambar 4. Rumus Bangun Triasetin

Menurut Widayat dkk [5], triasetin merupakan senyawa ester yang menghasilkan puncak-puncak serapan dalam analisis FTIR pada bilangan gelombang $1700-1750 \mathrm{~cm}^{-1}$. Pada tabel 
di atas menunjukkan puncak pada bilangan gelombang 1720,4 $\mathrm{cm}^{-1}$ yang tergolong dalam

Tabel 4. Panjang Gelombang Spektrum IR Gliserol [14]

\begin{tabular}{|c|c|c|}
\hline $\begin{array}{c}\text { Bilangan } \\
\text { Gelombang } \\
\left(\mathbf{c m}^{-1}\right)\end{array}$ & $\begin{array}{c}\text { Rentang } \\
\text { Bilangan } \\
\text { Gelombang } \\
\left(\mathbf{c m}^{-1}\right) \\
\end{array}$ & Ikatan \\
\hline 1043,4 & $1300-1000$ & C-O (Alkohol) \\
\hline 1639,4 & $\begin{array}{c}\text { Not } \\
\text { Interpretatively } \\
\text { useful }\end{array}$ & $\mathrm{C}-\mathrm{C}$ \\
\hline 2923,9 & $3000-2850$ & C-H (Alkana) \\
\hline 3423,4 & $3400-3200$ & O-H (Alkohol) \\
\hline
\end{tabular}

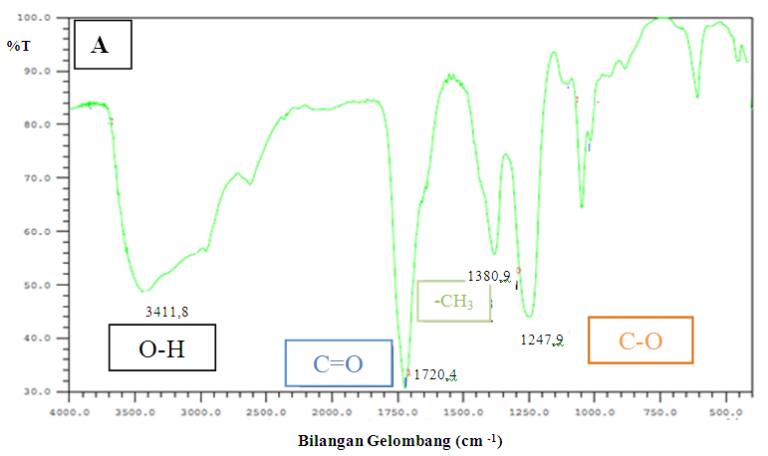

Gambar 3. (A) Spektrum-IR Triasetin Hasil Penelitian dan (B) Spektrum-IR Triasetin Hasil Penelitian Widayat dkk. [5]

Tabel 5. Panjang Gelombang Spektrum-IR Triasetin

\begin{tabular}{llll}
\hline Senyawa Triasetin* & $\begin{array}{l}\text { Hasil Esterifikasi } \\
\text { Triasetin }\end{array}$ & \\
\hline $\begin{array}{l}\text { Bilangan } \\
\text { Gelombang } \\
\left(\mathbf{c m}^{-1}\right)\end{array}$ & Ikatan & $\begin{array}{l}\text { Bilangan } \\
\text { Gelombang } \\
\left(\mathbf{c m}^{-1}\right)\end{array}$ & Ikatan \\
\hline 1233,77 & $\mathrm{C}-\mathrm{O}$ & 1247,9 & $\mathrm{C}-\mathrm{O}$ \\
1372,34 & $-\mathrm{CH}_{3}$ & 1380,9 & $-\mathrm{CH}_{3}$ \\
1743,65 & $\mathrm{C}=\mathrm{O}$ & 1720,4 & $\mathrm{C}=\mathrm{O}$ \\
3538,84 & $\mathrm{O}-\mathrm{H}$ & 3411,8 & $\mathrm{O}-\mathrm{H}$ \\
\hline
\end{tabular}

Hasil penelitian ini menunjukkan konversi sebesar 24,05\% yang lebih rendah dibandingkan hasil penelitan Widayat [5] dan Satriadi [10] yang menggunakan asam sulfat sebagai katalis dengan kondisi reaksi yang sama dengan penelitian ini, yaitu $67,6 \%$ dan $67,63 \%$. Penelitian ini menggunakan katalis asam nitrat. Asam nitrat tidak mampu mempercepat reaksi sebaik asam sulfat walaupun merupakan asam kuat. Hal ini berhubungan dengan konstanta laju reaksi. Konstanta laju reaksi katalis asam nitrat ini diduga lebih rendah dari katalis asam sulfat [10].

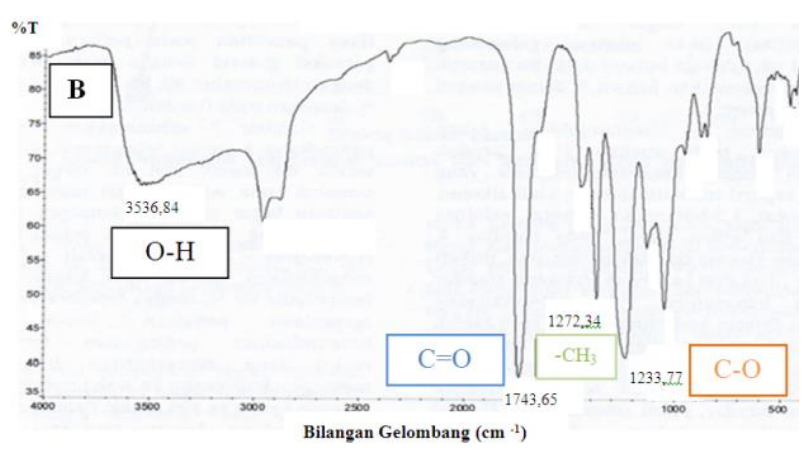

grup ester sesuai dengan produk triasetin hasil penelitian Widayat [5]

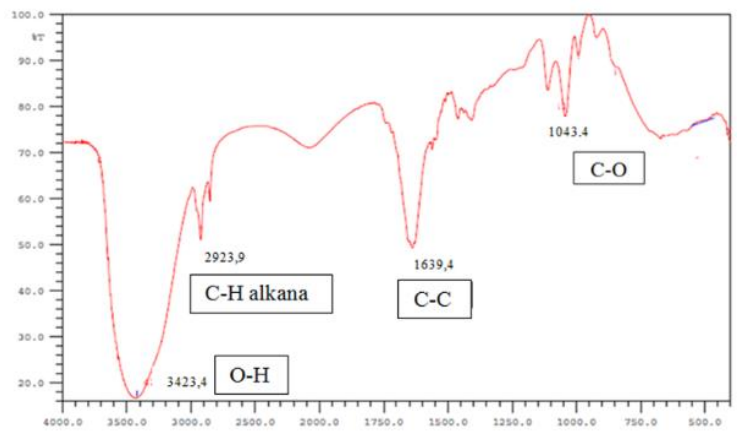

Gambar 2. Spektrum-IR Gliserol

Diperlukan penelitian lebih lanjut mengenai perbandingan laju reaksi katalis baik homogenus maupun heterogenus.

\section{Kesimpulan}

Metode pemurnian minyak jelantah dengan karbon aktif menghasilkan \% FFA yang memenuhi standar. Semakin tinggi konsentrasi karbon aktif, maka penurunan \% FFA-nya juga semakin tinggi. Biodiesel yang diperoleh dari transesterifikasi minyak jelantah dan metanol memiliki rendemen 95,28\% dengan kandungan metil ester yang sesuai dengan minyak kelapa sawit. Triasetin yang diperoleh dari hasil esterifikasi gliserol dengan asam asetat memiliki rendemen yang rendah, yaitu $24,05 \%$. Hal ini berarti asam nitrat tidak baik digunakan sebagai katalis dalam proses esterifikasi triasetin. 


\section{Daftar Pustaka}

[1] Chandra. Kebutuhan BBM, Ini Langkah Pemerintah [Internet]. Detik.com. 2016. http://finance.detik.com/energi/d-3152250 /ri-impor-50-kebutuhan-bbm-ini-langkahpemerintah.

[2] Setiawati E, Edwar F. Teknologi Pengolahan Biodiesel dari Minyak Goreng Bekas dengan Teknik Mikrofiltrasi dan Transesterifikasi sebagai Alternatif Bahan Bakar Mesin Diesel. J Ris Ind. 2012. 6(2):117-27.

[3] Ketaren S. Pengantar Teknologi Minyak dan Lemak Pangan. Jakarta: UI Press; 2008.

[4] Majid AA, Prasetyo D, Danarto YC. Pembuatan Biodiesel dari Minyak Jelantah dengan Menggunakan Iradiasi Gelombang Mikro. In: Jurnal Simposium Nasional RAPI XI FT UMS-2012. 2012.

[5] Widayat, Satriadi H, Abdullah, Handono IWK. Proses Produksi Triasetin dari Gliserol dengan Katalis Asam Sulfat. J Tek Kim Indones. 2013. 11(4):192-8.

[6] Kale S, Armbruster U, Umbarkar S, Dongare M, Martin A. Estserification of Glycerol with Acetic Acid for Improved Production of Triacetin Using Toluene as an Entrainer. In: Symposium of 10th Green Chemistry Conference. 2013. hal. 1-2.
[7] Wepoh H. Synthesis of Triacetin from Glycerol. Universiti Tunku Abdul Rahman; 2015.

[8] Hart H, Craine LE, Hart DJ. Kimia Organik. Diterjemah. Jakarta: Erlangga; 2003. 320322 hal.

[9] Srivastava A, Prasad R. Triglycerides-based diesel fuels. Renew Sustain Energy Rev. 2000. 4(2):111-33.

[10] Satriadi H. Kinetika Reaksi Esterifikasi Gliserol dan Asam Asetat menjadi Triasetin menggunakan Katalis Asam Sulfat. Teknik. 2015. 36(2).

[11] Arita S, Dara, Mata B, Irawan J. Pembuatan Metil Ester Asam Lemak dari CPO Off Gradei dengan Metode EsterifikasiTransesterifikasi. J Tek Kim. 2008. 2(15):3443.

[12] Soerawidjaja TH. Pengembanngan Biodiesel di Indonesia. Bandung; 2000.

[13] Suirta IW. Preparasi Biodiesel dari Minyak Jelantah Kelapa Sawit. J Kim. 2009. 3(1):16.

[14] Guthrie RD. Introduction to Spectroscopy (Pavia, Donald; Lampman, Gary M.; Kriz, George S., Jr.). J Chem Educ. 1979. 56(10):A323. 